\title{
Latent Heterogeneity in the Marginal Propensity to Consume*
}

\author{
Davide Melcangi \\ Laura Pilossoph \\ Federal Reserve Bank of New York ${ }^{\dagger} \quad$ Federal Reserve Bank of New York ${ }^{\ddagger}$
}

February 2019

\begin{abstract}
Recent work highlights the importance of heterogeneity in marginal propensities to consume (MPCs) out of transitory income shocks for fiscal policy, the transmission of monetary policy, and welfare. In this paper, we construct an estimator for individual MPCs using the Grouped Marginal Effects Estimator (GMEE), which optimally groups households together that have similar latent MPCs. The approach we propose is agnostic about the source of heterogeneity and estimates distinct MPCs as well as which households display these distinct propensities. We apply the estimator to the 2008 tax rebate and household consumption data from the Consumer Expenditure Survey (CEX), exploiting the randomized timing of payments as previously done in the literature. Our approach uncovers a large degree of heterogeneity in household MPCs, and permits the identification of observable characteristics that predict household MPCs.
\end{abstract}

${ }^{*}$ The views expressed in this paper are those of the authors and do not necessarily reflect the position of the Federal Reserve Bank of New York, or the Federal Reserve System.

${ }^{\dagger}$ Macroeconomic and Monetary Studies, address: 33 Liberty Street, New York, NY 10045, USA. Email: Davide.Melcangi@ny.frb.org

${ }_{\ddagger}$ Macroeconomic and Monetary Studies, address: 33 Liberty Street, New York, NY 10045, USA. Email: Laura.Pilossoph@ny.frb.org 